This item was submitted to Loughborough's Research Repository by the author.

Items in Figshare are protected by copyright, with all rights reserved, unless otherwise indicated.

\title{
Repertoires of aspiration, narratives of identity, and cultural models of mathematics in practice
}

\section{PLEASE CITE THE PUBLISHED VERSION}

http://www.sensepublishers.com

PUBLISHER

(C) Sense Publishers

VERSION

AM (Accepted Manuscript)

LICENCE

CC BY-NC-ND 4.0

\section{REPOSITORY RECORD}

Williams, Julian, Laura Black, Paul Hernandez-Martinez, Pauline Davis, Maria Pampaka, and Geoff Wake. 2019. "Repertoires of Aspiration, Narratives of Identity, and Cultural Models of Mathematics in Practice". figshare. https://hdl.handle.net/2134/8732. 
This item was submitted to Loughborough's Institutional Repository (https://dspace.lboro.ac.uk/) by the author and is made available under the following Creative Commons Licence conditions.

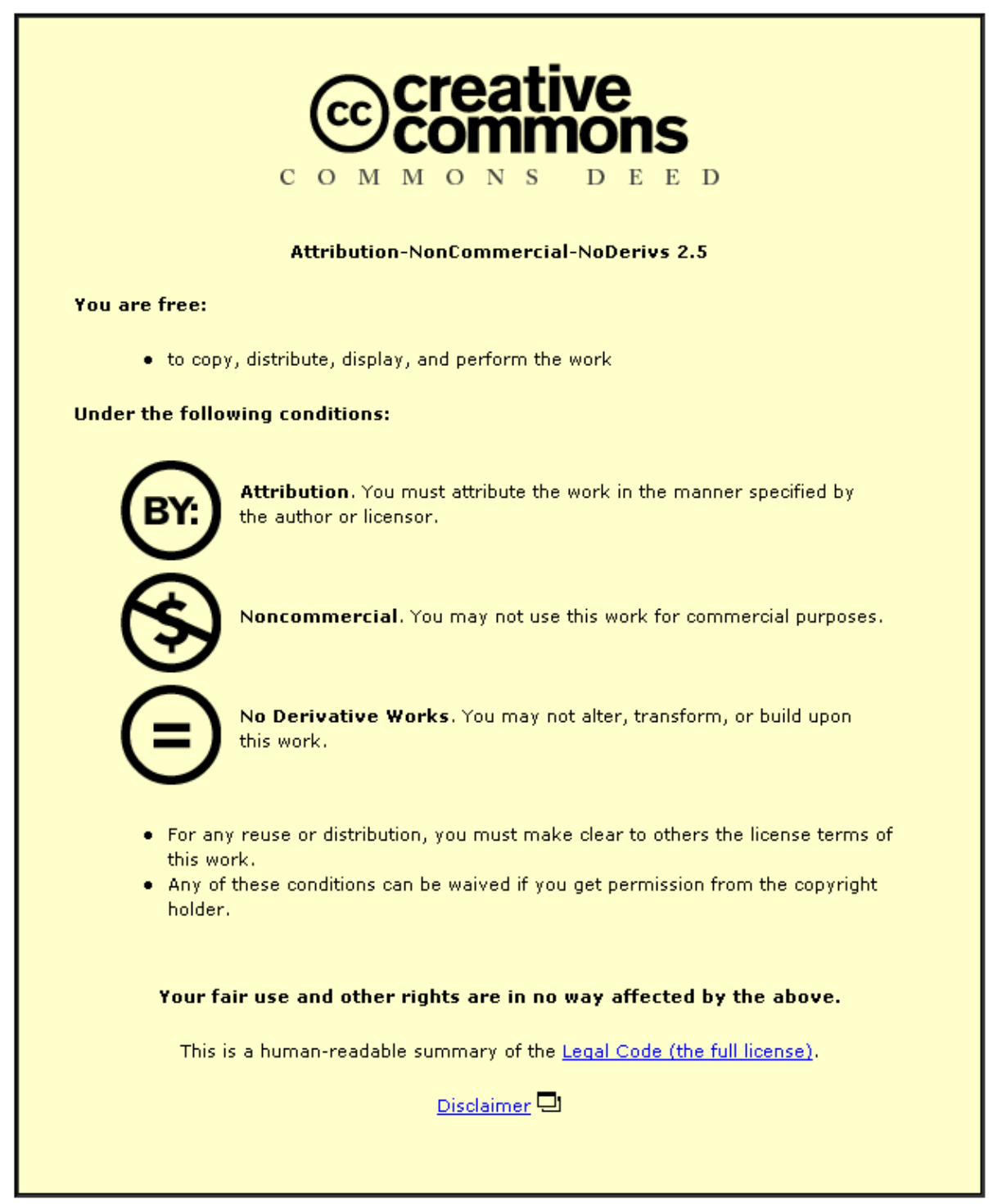

For the full text of this licence, please go to: http://creativecommons.org/licenses/by-nc-nd/2.5/ 


\section{REPERTOIRES OF ASPIRATION, NARRATIVES OF IDENTITY, AND CULTURAL MODELS OF MATHEMATICS IN PRACTICE}

Julian Williams, Laura Black, Paul Hernandez-Martinez, Pauline Davis, Maria Pampaka and Geoff Wake

The University of Manchester

\section{INTRODUCTION}

In this chapter we will draw on work from our project, Opening doors to mathematically-demanding programmes in Higher Education ${ }^{1}$ and in particular on four of the project's recent papers (Black, Davis, Hernandez-Martinez, Pampaka, Wake, \& Williams, under review; Hernandez-Martinez, Black, Williams, Davis, Pampaka, \& Wake, 2008; Williams, 2007; Williams, Black, Hernandez-Martinez, Davis, Hutcheson, Nicholson, \& Wake, 2007) to demonstrate three distinct methodological frameworks, based on 'discursive psychology', a narrative approach to identity, and cultural-historical activity theory (CHAT) respectively. The first two of these papers analysed interview data to gain insight into how different students formulate different aspirations and identities in regard to mathematics. The latter two increasingly draw on a broader set of case study data that includes observations of classrooms and interviews of observed students and their teachers, and indeed managers and principals in the colleges where the learners were studying.

In addition to grounding these three methodological approaches in the project's data, we aim to evaluate the adequacy of these approaches to understanding and explaining how identity is produced in practice. Although the substance of our results are of interest to mathematics educators, our main aim in this paper is to illustrate the different theoretical and methodological approaches and what they can offer researchers interested in identity. We finally will argue the need for discursive and narrative methodologies to be complemented by ethnographic-style case studies of social practice in order to produce 'explanations' of trajectories of identity. In particular, we argue that this requires a 'boundary' concept between the activity of doing mathematics (the mathematical practice) and the activity of storying one's self (narrating a biography) and accounting for one's aspirations.

We show how we use 'cultural models' in this regard: indeed we show how cultural models arising from classroom mathematical practice can be instrumental in students' accounting for their aspirations and in their narrative identity work.

1 We acknowledge the support of the ESRC-TLRP programme of research into widening participation, funded by ESRC.RES-139-25-0241. 


\section{PROJECT CONTEXT}

The project Opening doors to mathematically-demanding programmes in further and higher education (FHE) (www.lta.education.ac.uk/TLRP/) explores students' dispositions for further study, particularly in higher education, and particularly to study courses in which mathematics might be relevant. One part of the research involves a survey and quasi experiment, in which measures of 'disposition to study in HE' and 'disposition to study more mathematics' are constructed as outcome variables (as well as attainment grades), while process variables include 'teachercentred-ness of pedagogic practice' (as reported by the teachers themselves) and courses studied, and background variables include 'pre-test' measures (dispositions including grades) as well as gender, socioeconomic status and ethnicity. Thus for instance, we have been able to report that teacher-centred pedagogy has a significant negative relation with learners' disposition for further mathematical study (Pampaka, Black, Davis, Hernandez-Martinez, Wake, \& Williams, 2007). Such measures can provide evidence of statistically significant relationships that may influence policy makers and the 'State', but do not necessarily help practitioners in terms of gaining insights into how, when and why pedagogic practices 'work'.

Thus, to complement this quantitative study we conducted multiple case studies of students as they progress through a year or so of further education (usual age 1619 years). The data analyses from the students' interviews are complemented in later analyses by data from case studies in their colleges including classroom observations and interviews with their teachers. So, we are pursuing interviews with 40 students (at least three interviews each, transcribed) over the course of a year or so during which their early pre-university course studies gather pace and when they make decisions about university applications (the full interview sample, including the pilot group, used in some cross sectional analyses, is more than 50 students). This student sample was constructed to ensure that we included students likely to drop out of maths at advanced level due to 'risk' factors such as low previous mathematics grades, 'first generation into higher education families', following mathematics courses that are planned to end in one year rather than the usual two years, and so on. In interviews we (two full time research assistants and four of the main investigators were involved) ask about their biography, their dispositions and future intentions (we also have survey instrument data including dispositions that serve to locate these students against the canvas of a larger population). We also ask about their engagement in mathematics classes (some of which we observe).

It may be helpful to the reader to understand our rather particular study and sample: we focussed our questionnaire survey (initially $\mathrm{N}=1700$ ) and interview subsample (main study $\mathrm{n}=40$ ) on students who were studying (and so had opted to study) mathematics in the post compulsory stage at pre-university level, (normally aged 16-17 years). But the sample was constructed with a particular aim to include targeted students who are - according to statistical indices, involving demographics, prior grades and maths course chosen - prone to drop mathematics before they get to university and so likely not to choose mathematically demanding courses at university. The sample comes from the classrooms of $\mathrm{AS}^{2}$ level teachers in 5 case study colleges, which were chosen to represent inner-metropolitan, 
'deprived' and 'competitive' city, and rural colleges, 'open access' $6^{\text {th }}$ form and further education colleges, and some diversity of teaching and programmes. Thus our target student sample over-represented students with relatively weak mathematical prior attainment, from populations in poor or inner urban contexts and so on. Some of the demographics are visible in Tables 1-3 below. Because we focussed relatively strongly on urban, deprived and metropolitan colleges, ethnic minorities were also over represented, especially in the interview sample. Nearly half the total sample is ethnic minority: this can be compared with English average of less than $10 \%$, but a London average of nearly 30\%, according to the 2001 census (see National Statistics Online, 2008 data). (It is believed that this has increased since 2001, with large influxes of migrants from Eastern Europe. Some estimates also exist of millions of inhabitants who do not register in official censuses). Even more significantly, half the sample is classed as 'hard pressed' demographically, which corresponds to the poorest sector of UK society. Finally, the sample combined class, gender and ethnicity in 'intersectional' ways. Thus, there was a significant group of male students following a vocational engineering programme that was largely immigrant or ethnic minority, and another large group of white working class students from a deprived and somewhat isolated city 'estate' that was largely female.

For the purposes of this study, then, UK 'culture' is multiple by virtue of being 'represented' by a diversity of students with very different social and cultural backgrounds. The inclusion of aspirational migrants and middle class students (geodemographic areas 1, 2, and 3), by contrast with those from white working class poor backgrounds, is especially important in the UK educational context today, as there is increasing political interest and concern that British white working class culture is being marginalised. In regards to educational performance in general and university and higher education in particular, students from poor working class backgrounds are under-represented, but when poverty is controlled for, whites are even more disadvantaged than other ethnicities. To this also, gender disadvantages can be added: boys generally do less well than girls, and the difference is much stronger in some ethnicities than others (see DFES, 2008 data).

Willis' (1977) ethnography showed how schools fail white working class 'lads' in the Midlands, and how working class culture plays its part in this: the charismatic performance of leading lads who mature early, who 'take the piss' out of the pompous, the powerful, and especially the 'earoles' (peers in school who passively and effeminately 'listen' to teachers). He provides a rich description and perhaps causal explanation of their growing dissociation from education. Evans (2006) goes further, showing how heterogeneous white working class culture actually is, even in very strong local and historic communities. Bourdieu (1984) showed convincingly how a class can 'distinguish' and recognise itself culturally from generation to generation: for Evans (2006), the poor whites recognise themselves in part through their rejection of the upper classes - 'not being posh' -

AS or advanced subsidiary is the first half of an A level (advanced GCE) as well as being a stand- alone qualification 
and of all educational or religious authority in general (the white poor are strongly secular, in stark contrast to the incoming migrants and largely religious ethnic minorities). But this is conflicted: the parents want the best for their children's own education, ideally to 'get on', even while this entails 'getting above oneself'. Working class distinction then may involve expressing contempt for those that get on in the world, especially as this involves moving away from the estate or 'manor' to 'other', posher areas. To this Evans adds a vivid description of the 'levelling' of working class children, that is, bringing them down to their 'proper' level. Thus, we are told, 'Anne', tells of a levelling incident (Evans, ibid, 71) when her boy Tom, aged 5, during his christening ceremony in church was bribed by his uncle for five pounds (about 7 Euros) to "go up to that man in the black dress (the priest), and call him a $\mathrm{f}^{* * * \text { ing }} \mathrm{c}^{* * \mathrm{t}}$ " - whereupon the boy promptly earned his first fiver presumably to huge guffaws from his uncle. Bringing the powerful and pompous down also goes hand in hand with 'standing up for yourself', but 'not getting above your station', 'having a laugh' and using rude language, or 'being common'. The contrast between the home (and later, especially for lads, the street) class culture and that of school, especially the values, rules and language of schooling, can then be stark: and it is especially so for the boys. Needless to say, Tom is difficult for the teachers to manage at school, and when taken on an excursion it is one of the mothers Sharon - who describes herself as 'common-as-shit' - who undertakes the job of controlling him using language and 'manners' that the teachers can't adopt "we don't swear at the children here". Thus, the culture clash between home and school, which Bernstein (1996) argued accounts for class reproduction and educational under-achievement, should be seen as taking particular local, gendered, classed, 'multicultural' forms.

So in our study, the 'multicultural' backgrounds of the students should really be understood as the manifold socio-cultural and cultural-historical contexts, which equally includes gender, class, ethnicity, religion, nationality, and the many permutations and intersections of these. In this scheme of things, white working class masculinised backgrounds are of at least as much educational interest as and in some ways more so than - ethnic minority or migrant backgrounds.

Another important feature of the study context was that the interviews with the students (spread over more than a year to allow time for a 'trajectory' to emerge) were mostly conducted while we engaged in fieldwork that included observations of their classroom practices and interviews with their teachers and leaders of their institutions (so-called heads of departments and sometimes principals). Many students were also following an innovative mathematics course which is designed to widen participation of students who might not otherwise be studying mathematics at this level, but which terminates before the students leave college and go to university (called "use of mathematics" AS level.) Additionally, two colleges became known to us because of their innovative work. Thus we aimed to triangulate distinct classroom and institutional practices with their different students' accounts and trajectories of identity.

However, the point is also that this is a rather particular student sample, and we do not aim to generalise substantive results to the UK population of students of this age. Rather the research strategy is in each case 'multiple case study', albeit with different units of analysis in the three cases, and we aim to generalise to theory, 
analytically (Yin, 1989). In this chapter we focus on illustrating the merits of three methodological positions in coming to understand students' mathematical identities, and the reader is advised to consult the project's other papers for more substantive details.

\section{ANALYTICAL OVERVIEW}

Our first analysis (drawing on Hernandez-Martinez et al., 2008) of interview data is cross-sectional, thematic, and draws parsimoniously on the concept from critical discourse analysis of an 'interpretative repertoire' of Potter and Wetherell (1987). This reveals learners' 'ways of talking' about their educational and life aspirations (and how mathematics fits into these) and are interpreted as categorising students' ways of interpreting this 'aspirational' aspect of their world, or of telling this aspect of their realities, their experiences, this social identity. The fact that these are 'told' (that is, to us, in interview) of course implies that they are 'common sense', or at least that they are taken by the students to be socially acceptable, social representations of themselves. By categorising these repertoires across the data set we 'map' these linguistic resources against background variables (of our special - it must be admitted - sample) and thereby provide an 'existence proof' of repertoire 'styles'. By repertoire style we refer to the dominant repertoire adopted by a student in this context (when there is such a dominant use).

In this analysis the concept of 'repertoire' is understood in the discourse analytic sense, after Potter and Wetherell (1987) and others, rather than that due to Wenger (1998) in that we do not need to assume that these repertoires are in any sense (even partially) constitutive of any particular 'community of practice' or even a 'social group' (of learners, say). This is important because the validity of the empirical results does not require such theoretical commitments, and so can be accepted as such. This principle of parsimony is, we argue, worth preserving where possible.

The result of this first analysis is that we identify four distinct repertoires and that each of these turns out in fact to provide 'styles' for most of the sample, though there are some students who use more than one repertoire in their interviews and are therefore not classifiable using one style. More importantly, these styles are social-culturally related to the background of the student: for instance, we find that the 'idealist' style is predominantly a white working class repertoire style, while 'becoming a success' is the predominant style of immigrant

or minority ethnic students. Each aspirational style has some implications for mathematical identification, and the empirical fact that these styles are socioculturally marked is therefore pertinent to understanding how mathematical identity may be intertwined with social, cultural background factors. But this analysis does not yet explain how background factors influence or mediate mathematical aspirations or identity.

The second analysis of some of the same data is then narrative/biographical, after Bruner (1996). In this analysis we hold on to the 'whole' story of the individual student and try to make sense of their trajectory of identity, their cultural history, their present experiences and their imagined futures (drawing on Williams et al., 2007). Each individual story is a holistic construction by the 
interviewer/research analyst and the student. The coherence of the narrative relies, inter alia, on its temporality and plot (Bruner, 1996; Kaasila, 2007). The story can also be thought of as an 'account', in the discursive psychological sense (Potter \& Wetherell, 1987) but it is more, in that its structure demands a narrative, biographical form that weaves together many elements into a whole. Bruner (1996) has outlined the essential elements of the narrative form of construal of cultural 'reality': temporal structure, generic particularity, reasons, hermeneutic composition, canonicity, ambiguity, 'troubles', negotiability, and historical extensibility (pp. 133-143). Temporality, reasons and troubles are most significant for gaining purchase on a trajectory of mathematical identity and its attendant conditions, which is of particular concern to our research project. In these narrative analyses, then, we argue that it is possible to understand how aspirations can evolve, how identities grow, and how key moments are said to deflect trajectories in significant ways for the students. This then begins to produce the 'explanations' we found missing in the first analysis, but they are still essentially discursive constructions, and can be criticised as suffering from being after the event, and self-serving.

However, our project seeks further to understand how student engagement in practice, for example, in classroom mathematics, might partially explain the significant attendant conditions and critical moments that students tell of in their stories of self-identification. We therefore look for key cultural elements that students use to account for their trajectories into or out of mathematics and for their mathematical identities, and how these might be found in the practices in which they engage - particularly in their classroom mathematics practices. We adopt the framework of 'cultural models' in 'figured worlds' to achieve this, borrowing from Holland, Lachicotte, Skinner, and Cain (1998). This choice was adopted as it is most obviously consistent with cultural-historical activity theory (CHAT), in that these cultural models may also mediate classroom practices and pedagogic discourses.

\section{CULTURAL-HISTORICAL ACTIVITY THEORY, CULTURAL MODELS AND SOCIAL IDENTITY}

We take a cultural-historical activity theory (CHAT) perspective on identity in practice. The founding corpus of CHAT is usually attributed to the original Marxist troika of Vygotsky, Leont'ev, and Luria (see Daniels, 2001), as interpreted and developed in multicultural contexts in later generations by Cole (1996), Engestrom (1999) and others. While for Vygotsky the key unit of analysis of mind is action mediated by cultural tools, Leont'ev (1978) extended this unit to collective, joint 'object-oriented' activity, mediated also by the division of labour in the community and its attendant social norms and rules that position subjects in their actions and coordinate them with those of others in the activity. This 'positioning' is important

This account is a redraft of the CERME conference paper Williams et al. (2007) and informed by our papers in the IJER special issue on 'subjectivity'. 
in relating subjectivity to power into the analysis. Latterly also, Engestrom, Cole and others - in what they called 'third generation activity theory' - expand the focal unit to 'interacting' activity systems, where boundary objects and crossers may interface two or more activity systems. This introduces contradictions into an activity system from outside, which is apt to our analyses. Thus, meanings and even social identities brought into school from home or elsewhere can be seen as boundary objects that can introduce contradictions in schooling activity and vice versa (see Roth \& Lee, 2007; also Roth, Hwang, Lee, \& Goulart, 2005; Stetsenko \& Arievitch, 2004; Williams \& Wake, 2007a, b; and www.edu.helsinki.fi/activity/ people/engestro/). Scholars such as Wertsch, Wells and others have also incorporated Bakhtinian and even Hallidayan discursive and dialogical constructs of voice into CHAT theory (see Holland et al., 1998; Gee, 1999, 2001; Wells, 1999; Wertsch, 1991). Even Bruner's account draws powerfully from the Vygotksyan perspective (Bruner, 1996).

Identity is here seen as emerging from engagement in socio-culturally mediated activity, specifically in collective, joint object-orientated activity. Because 'collective' activity requires intersubjective coordination, implicated in the division of labour, all 'actions' imply a subjective orientation that must itself be culturally mediated, usually and most obviously through language. But such subjectivity then implies an engagement with 'social identity', and with its 'cultural models' (more on this later). Being positioned, and especially positioning oneself in activity, then, constitutes a work of identity. In CHAT we say that the acquisition of a social identity involves a subjective orientation in an activity which is mediated by that social identity in joint work with others. This social identity may then be progressively internalised. Thus, being positioned by others leads to selfpositioning.

This happens because the use of 'psychological tools' in communicative activity is always double-edged. Concepts and identities adopted in social interaction come reflexively to be used internally, on the self. Thus, one 'becomes' what one 'does' and, importantly, one comes to 'think' what one 'says': reflexivity and self- and social positioning ensures that we become the player that we perform (Jenkins, 2004). While 'activity' is always driven by a 'community' motivation, the individual is always 'positioned' (by self and others) in a division of labour, held in place by 'rules' governed by cultural norms and expectations. But we must beware seeing this too mechanically, this internalisation always involves a transformation and should not be understood as a copying of the social onto the mental planes. This is because internalisation involves the activity of reflection, and this is mediated by cultural models in figured worlds that are not just reducible to the activity system at hand - reflexive activity draws on reflections of the self in other activities too.

Holland and Quinn (1987) developed the notion of 'cultural model' to describe the culturally derived nature of models, rules and schema such as those used by students in their identity work (for example, undergraduates' dating identities). Gee and others have expanded the concept to include everyday cultural concepts and conceptual frameworks that govern what we can perceive, but also what we can tell, that go to make up 'discourses' that mark out identities. Thus, cultural models provide resources for reflective identity work. 
We find the more recent metaphor of a landscape of 'cultural models in figured worlds' even more helpful (see Holland et al., 1998); one's narrative of identity can be told as a path through our available 'figured world' of cultural models, ideal figures and so on. Thus, a male student, thought to have Asperger's Syndrome told us of their identity as someone who "likes to work alone ... and always needs to know there is a 'right' answer." Such self-identification might lead to such a student being regarded as a budding mathematician - and so they might come to regard themselves as such. That is always assuming the dominant cultural model of mathematics as a 'right/wrong', 'black-and-white', solo activity. Many tell of mathematics as a 'hard' subject; a student who wants to position him/herself at a distance from mathematics may say "mathematics was too hard for me". But for another, it turns out, mathematics is hard 'but challenging'. Thus, the 'cultural model' of mathematics that includes 'maths is hard', may be turned this way and that as a story is negotiated though a complex, figured world.

Thus, in our theoretical framework, students may learn cultural models in practice from social activities in general and classroom practice in particular, and these can provide tools for students' construction of an identity. Students are presumably not totally free to narrate themselves as they wish using these models, first because they may not wish to align themselves with a particular positioning (for example, 'being a geek' may not be good for a social life) and second, because positioning oneself is always a 'claim' that may be subject to social confirmation, or dispute by others (for example, being 'good at maths' may not survive a poor examination grade).

Thus, essential empirical questions to answer are then: "how can/do students draw on cultural models in telling stories about their identity (in relation to mathematics)?" or "how can/do these stories produce/reproduce a disposition to study mathematics, or not?" and "where/when in practice do students access/learn these cultural models and dispositions?"

\section{RESULTS}

\section{Cross sectional analysis of 'interpretative repertoires' of learners' aspirations}

Having outlined our project's choice of 'cultural models in figured worlds' as the cultural resources for narrating the 'self', we should explain why we adopted the alternative, less theoretically loaded perspective of 'interpretative repertoires' for use in our cross sectional categorical analysis of the students' aspirations. The analysis was conducted on the interview data cross-sectionally at one point in time, focussed on themes related to the learners' explanations of their aspirations for higher education, why they have formed these aspirations and how mathematics fits into their imagined future HE courses and choices. Thus this initial analysis had no prior commitment to categorising models known to us to arise in classroom practice or in the culture, no temporal analysis or trajectory and initially no analysis by 'learner' demographics (this came later). As such it seemed parsimonious to stay close to the phenomenon in the data set as a whole, and to initially adopt as little theoretical baggage as possible that policy makers or others might be inclined to dispute. 
Thus, the term 'repertoire' implies no particular commitment to analysis of any factors and data from social practice, 'outside' the discourse. Methodologically, this can be considered either an advantage or a disadvantage, depending what one wants to achieve and what data is available. In the event, from this cross-sectional thematic analysis of our students' utterances in interviews, we were able to identify four categories of 'repertoire' (see Hernandez-Martinez et al., 2008). These were as follows:

The repertoire for "becoming a success" is adopted by students when they say "I will go to university... because ... I want to become someone". Education is seen here as a means to the end of social progression, "if you don't do nothing, you won't become no-one" (José). Usually such students plan to go to university to develop a career in areas such as business, medicine, law, accountancy, and so on where the university course clearly marks out a professional, successful career trajectory. Money or other indications of status may be mentioned specifically, as in Takeshi's comment: "I would like to be in my own office in charge of a company, driving a really nice car and ... I don't know where I'll be like living but I know I'd be travelling, doing business around the world and stuff." Parental encouragement is strongly visible in the typical account, "My mum and dad have really high expectations... [of me] to go to university ..." (Takeshi) though such students will usually have internalised this ambition themselves. In this repertoire mathematics is instrumental, a means to an end, though it may also be seen as useful as well as a necessity (for example, for an engineering course, or even accountancy).

In sharp contrast, we find a repertoire 'for personal satisfaction', wherein aspirations are described as being for development of the self. In this repertoire the students will choose a course that interests them, or even go into 'music' or the 'army' if that is their 'thing'. Pressure from parents seems absent, "They [parents] are the same as me - if I want to go I can go but at the end of the day I don't think it would ultimately achieve what I want to do with my life ..." (Alice) The choice of mathematics is here associated with maths being fun: "I'm really enjoying maths. Maths has to be my favourite subject now..."

Another repertoire we call 'idealist' involves the pursuit of an ideal or 'dream'. Gemma (see below in the holistic analysis) identified a dream to become a mammalogist after seeing the film "Free Willy" at the age of eight. Their ideal or dream quite often was inspired by the media (another example: the TV programme 'CSI' was cited by Adele in regards to wanting to become a forensic scientist). Gemma's ambition seemed to develop and grow with time, and she has quite a good idea what she will need to do to achieve this (having had careers advice in secondary school). In many cases, however, there was a lack of practical awareness of what might be involved: Sonia for instance declared an ambition to study computing, but had little idea about programming or what this might involve. Many of these students spoke of their families being supportive of their ambitions despite (or because of) not having been to university themselves, but their parents ambitions for them seemed not to be stressed in this repertoire. In fact Gemma specifically says she wants to go to university so as not to end up like her Mum.

Similarly mathematics is incidental in this repertoire. Thus Adele says of her ambitions to become an architect and, specifically, to build houses in California: 
Just a dream I have [had] for a long time ... I've ... watched programmes and things and I like interior deign as well and I thought - designing houses - I like that as well... I need maths and other subjects I am doing, but I think when I go to university it will all be in one [course].

Finally, we identified a strongly distinct 'vocational' repertoire that was adopted mainly by students on vocational engineering programmes that were studying mathematics as part of and also separately from their engineering course. This was the only repertoire in which mathematics was described clearly and convincingly as 'useful' rather than instrumental. Malik for instance says: "Maths is the main part of electronics... you need maths to calculate stuff, that's why if I don't do maths I can't do electronics."

In addition it was possible to categorise most of the 40 students using these repertoires as predominantly using one repertoire (we used the term 'repertoire style' to describe the repertoires of these students). It transpired that the students adopting a particular style had specific demographic, ethnic and gender characteristics: in Tables 1-3 we show the styles crossed with (1) geodemographic area: this is the so called Acorn classification of postal addresses into 5 socioeconomic classes, with class 5 being 'hard pressed' financially, and 1-3 being various grades of middle class; (2) self-reported ethnicity, where here we grouped the Indian sub-continental countries as 'Asian', and Black Caribbean, African or British as 'Black'; and (3) gender.

Table 1. Repertoire types by geodemographic area

\begin{tabular}{|l|l|l|l|l|l|r|}
\hline \multirow{2}{*}{ Repertoire type } & \multicolumn{5}{|c|}{ Geodemographic Area } & \multirow{2}{*}{ Totals } \\
\cline { 2 - 6 } & 1 & 2 & 3 & 4 & 5 & \\
\hline 1 (success) & 0 & 2 & 2 & 2 & 4 & 10 \\
\hline 2 (satisfy) & 2 & 2 & 2 & 0 & 0 & 6 \\
\hline 3 (voc) & 0 & 2 & 0 & 0 & 6 & 8 \\
\hline 4 (ideal) & 0 & 0 & 1 & 1 & 8 & 10 \\
\hline unclassified & 1 & 1 & 1 & 1 & 2 & 6 \\
\hline Totals & 3 & 7 & 6 & 4 & 20 & 40 \\
\hline
\end{tabular}

Table 2. Repertoire types by ethnic background

\begin{tabular}{|c|c|c|c|c|c|c|}
\hline \multirow[t]{2}{*}{ Repertoire type } & \multicolumn{5}{|c|}{ Ethnic Background } & \multirow[t]{2}{*}{ Totals } \\
\hline & $\begin{array}{l}\text { White } \\
\text { British }\end{array}$ & Black & Asian & Chinese & $\begin{array}{l}\text { Other } \\
\text { White }\end{array}$ & \\
\hline 1 (success) & 1 & 4 & 3 & 1 & 1 & 10 \\
\hline 2 (satisfy) & 6 & 0 & 0 & 0 & 0 & 6 \\
\hline 3 (voc) & 2 & 3 & 1 & 1 & 1 & 8 \\
\hline 4 (ideal) & 10 & 0 & 0 & 0 & 0 & 10 \\
\hline unclassified & 2 & 3 & 1 & 0 & 0 & 6 \\
\hline Totals & 21 & 10 & 5 & 2 & 2 & 40 \\
\hline
\end{tabular}


Table 3. Repertoire types by gender

\begin{tabular}{|c|c|c|c|}
\hline \multirow{2}{*}{ Repertoire type } & \multicolumn{2}{|c|}{ Gender } & \multirow{2}{*}{ Totals } \\
\cline { 2 - 3 } & Male & Female & \\
\hline 1 (success) & 7 & 3 & 10 \\
\hline 2 (satisfy) & 5 & 1 & 6 \\
\hline 3 (voc) & 8 & 0 & 8 \\
\hline 4 (ideal) & 3 & 7 & 10 \\
\hline unclassified & 3 & 3 & 6 \\
\hline Totals & 26 & 14 & 40 \\
\hline
\end{tabular}

Thus, we concluded that repertoire 'styles' were strongly associated with certain socio-cultural background characteristics: in this perhaps unusual sample these were 'classed' (as in the largely female white working class 'idealists' contrasted with the mainly middle classed 'personal satisfaction' repertoire). The ethnic minority preference 'for success' is also striking, and resonates with findings about immigrant, aspirational communities elsewhere (Sfard \& Prusak, 2005). Unfortunately it is not easy to disentangle background factors of class, ethnicity and gender as so many of our small samples were black, male and also vocational (and similarly another numerous percentage were white, working class and female).

The analytic conclusion is that: (1) the 'repertoire' methodological approach yields a particular abstract, analytic thematic generalisation from students' talk which in this case allowed categorisation of most of the individuals' interviews in the sample into 'styles' (that is, few use more than one repertoire in their interview); (2) there is an empirical relationship between students' background variables and the repertoire styles they display in interviews when telling us of their aspirations and identity; and (3) each 'style' is associated with a different perspective on mathematics, which may be connected to how mathematics serves this 'style'.

The empirical relationship between 'style' and 'class/gender/ethnicity' is suggestive, and we argue that this line of work needs to be completed (a) over times and occasions with the current sample; and (b) with other samples (including some more 'mathematical' cohorts for instance). The notion that different students perceive mathematics in qualitatively different ways related to their wider or 'leading' aspirations and identity may also have significant practical implications for pedagogy.

However, what this methodology misses is a truly 'concrete', 'societal' and 'cultural-historical' explanation of how these students' discursive styles have become established, and what they might mean for identity. This would involve a genetic explanation, and suggests that a deeper analysis of the production of narratives may be needed over time. To achieve this, a discourse (perhaps a repertoire) has to be understood in a wider context, as a cultural-historical artefact, and as the result of a particular discursive activity. This is the purpose of adopting 'cultural models in figured worlds' as the unit of analysis, which provide a resource for identity work that has a cultural, historical and social source which involves activity outside of the specific community of discourse in focus. Indeed some social learning theorists (for example, Wenger, 1998) use the term 
'repertoire' in more or less this same sense: a repertoire is a set of discursive and other resources for identity work in play in (and so borrowed by members from) a particular community of practice.

However, the emplacement of cultural models (CMs) within CHAT does highlight some differences with Lave and Wenger's social learning theory. Specifically, CMs must be seen as artefacts with a cultural history. Thus, we recognise that CMs do more than provide resources for identity work as such, and they may not obviously 'belong' to a community of practice. Gee (1999) cites 'coffee' as an example of a CM: he suggests that it threads together many different meanings across different, connected cultures, from the grower of beans in Brazil to the consumer of lattes in Starbucks. He suggests though that there is a recognisable trace of the object (and its ideal conceptual form) across these cultures (Gee, 1999). To this one might add the historical context: such threads connect cultures across time as well as space. The connections across time are critical to narrative construction, as we will see in the next section.

\section{Biographical narrative analyses of identity ${ }^{4}$}

In the following we examine two cases of students who both chose to do advanced mathematics despite having a difficult time at their previous secondary school: in their interviews they used some of the same models as resources but in very different ways, partly reflecting their very different experiences in their current college mathematics programmes. They would both be categorised as white working class, from areas with low rates of participation in HE. Though one comes from a relatively homogeneous, isolated 'white enclave' on the edge of a city where minority ethnicities are barely visible, the other mixes in a multi-ethnic, inner city area. They are chosen for report because, despite having similar demographic categories, they provide a sharp contrast: one engages with mathematics in her classroom as a sociable activity in which she is always 'having a go'. Despite many difficulties and a weak background, and despite 'dropping out' for a while, when we leave her Gemma is still hanging on with her studies of mathematics. The other, Lee - despite having a stronger mathematics grade to start with - is withdrawn and even isolated in his class, positioned as being 'struggling' by the teacher; when we last interviewed him he has dropped mathematics and gone on to university to study non-mathematical subjects. One might think that the common cultural model 'maths is hard' is one that is used by low attaining students to speak of their dropping out of the subject, and this is the way the model comes to be used by the student who is becoming isolated from mathematics. However, for the 'engaged' student (Gemma) it becomes used as a positive resource for narrating herself as an engaged mathematics learner.

Gemma says she will be the first from her family to go to university. In fact she cannot name anyone she knows in her circle of friends and family who has been to university. But there is no question in her mind that she will go, she says, "I've been going to uni since I was eight". She has lived 'locally' all her life in a community that has all the 'poorest' social indicators. Her principal and teacher described, with almost ironical pride, the local community as sitting regularly at the bottom, or near the bottom, of every league table of performance and social

4 This section of results is developed from the CERME paper by Williams et al. (2007). 
index of deprivation the government has produced. Gemma tells us that her mother's work as a cleaner and shop worker is stressful, which has helped to motivate her as "I see my mum, like, working in a shop and cleaning and I don't want to do that, so that's kind of influenced me in my own work not to follow that path cos she gets stressed out and stuff'. Gemma tells us several times that her mum has been very supportive of her and encouraged her ambitions all her life (as has her mother's partner). She did well at Primary school: "I was always into books at school and I was always levels ahead". She said that getting level 5 - a very high grade - at age 11 in the National tests was an important marker for her. She experienced her catholic primary school as relatively, compared to secondary, 'inspiring'.

At age eight she decided she wanted to become a marine biologist so she could work with orca whales: "I've just always taken a fancy to orcas, ... Killer whales, ... Free Willy is my favourite movie [laughs]." Even though her mother thought she would 'get bored' with this particular ambition, Gemma has stuck with it and her mum has continued to support her; she had advice during secondary school from the 'connections' service and knows exactly what she has to do in her AS and A level grades in science and maths to get to university and then to do a $\mathrm{PhD}$ in marine biology. She knows she will spend six years at university and which one she wants to go to for her studies, as it has a connection with research into Orcas. In fact she tells us that the field she will need to follow to get to work with Orcas is more specialised, those who study big sea animals are called marine mammalogists, and "you have to be one of the top ones" to get into it.

Her experience of secondary school was very mixed, with classrooms being boring and classroom behaviour off-putting. The teaching was often uninspiring and she lost interest for a while: "From when I went to secondary school I lost interest in quite a lot of my study (...) at [primary school] there was more passion in it while at secondary school it was just "you've got to get through this." In contrast to her self-ranking in mathematics at Primary school, she says now "I wouldn't class myself as that good but maybe a bit above average". However, she describes maths as being 'challenging' rather than hard: “. . there was a lot of noise in the class ... [Int: disruptive?] yes; but I enjoyed it and it was a challenge as well ..."

Gemma got a modest grade in her final mathematics examination at age 16, and then did a statistics course, not being allowed to do the higher mathematics course for some reason. She would be considered a 'high risk' according to statistical trends at post-16, and in many colleges she would not be allowed onto the advanced mathematics course. She says she was worried she might not be able to cope with the algebra on her current course but actually feels she is doing well, and is enjoying maths now, “... it's a good system here: it gets the whole class involved and you get to hear how others do it and if it's better you can learn", which she compares to the dominant teaching practice in secondary school which was "boring and you forget it ..."

Her attitude to mathematics seems to have undergone a transformation since going to 16-19 college: "I am liking maths as much as I like biology which is my favourite subject ... so I'm getting really ... liking it compared to before." She explains why: Maths is more 'engaging' and she can express her opinion and hear what others have to say - she even mentions the interactive work with white boards and posters ... and maths is now described as 'fun'. 
This story - we call it a 'restorying' as it has been constructed by us from her interview - tells us several interesting things about her identity in relation to further study, higher education and mathematics. While her family background does not provide any 'role models' of people who went to university, she has developed an ambition that her family supported, and her mother's 'stressful' experience of work has influenced her positively. Her childhood ambition has been nurtured by family and shaped by the education service, and has matured into a career ambition. She knows she will need maths, challenging/hard or not, to achieve her ambition. But recently her enjoyment of mathematics seems to have returned and we can speculate that this will help in some way: we will see when we meet her again in six months time.

The model of a marine biologist and the inspirational film "Free Willy" seems central to her particular story. Many students of this age, just beginning at $6^{\text {th }}$ form of further education (FE) college, simply say "everyone I know is going to university" or even "I like science so I'll probably do something in the sciences but I am not sure what yet." However, the principal of Gemma's college told us that stories such as Gemma's are not unusual: one boy who had been on a work placement developed a specific ambition to work on a particular machine in an aircraft laboratory, and had worked it out that he would need to have a degree in aeronautical engineering to get into the necessary training programme in the aerospace industry. Thus we speculate that this might be a more common characteristic of some narratives of students from class backgrounds that do not provide many personal 'models' of university graduates in their community or family circle.

The particular way that Gemma constructs herself as having a positive relationship with mathematics might be relevant here, we speculate: her early imagined lifestory of 'becoming a marine biologist' comes together with her success in primary school, and "getting a level 5". As she develops her plan in secondary school she finds out that mathematics will be important to becoming a science student at university. This apparently positive synergy could perhaps have been expected to be dampened or even destroyed by a dull experience in secondary school, but (i) she is at least as good as the average of her peers in mathematics, and (ii) her family - especially her mother - encouraged her, and she finds energy from the thought that she does not want the stress of her mother's life as a manual worker.

We have speculated here that Gemma's positive disposition to study mathematics is in part at least sustained by her imagined lifestory of a university science career leading to a career as a marine biologist. We see other important sustaining resources as well, such as her success in primary school, her relationship with her peers and her recent positive experience of maths learning. These resources are important in providing her story with energy, and we imagine some were central to her in Primary and others later in secondary school. But we suggest that in her story now there is a prominent central 'leading thread' in her workambition: this seems to be the central element that provides for a 'positive disposition' towards mathematics, which in turn encourages her to see maths as a challenge rather than too hard. 
Let us consider for a moment the way a life story like Gemma's comes to be imagined: and also, by way of contrast, let us consider how the story, with much the same resources, might have been different. Gemma accepts, but makes use of the notion that mathematics is 'hard' for her: she posits maths as 'challenging' and she likes a challenge. But we know that for other students, mathematics is 'hard and dull', or 'too hard' and thus becomes something to be avoided. Within another lifestory, Gemma might well have adopted this notion as a means of representing a different disposition, of telling a story of a different person and imagined life. Lakoff and Johnson (1999) analysed the metaphor of 'life as a journey' and this seems apt to our present analysis. The 'imagined journey' in Gemma's case has a clear beacon in the distance, envisioned for her initially in film, and through other media later. In her narrated 'troubles', she meets many obstacles along the road, but also resources: she avoids the secondary school abyss and identifies a challenging climb there. There is an imagined slough of despond in future manual labour that she strives to avoid. In some cases perceived obstacles turn out to be friendly, what was said to be 'hard' to do becomes perceived as 'challenging'. Yet each 'resource' has a potential downside: if one experiences failure too often perhaps 'challenging' will become 'too hard', and the immediate part of the journey too difficult.

On the face of it a 'cultural model' seems to afford a way of overcoming an obstacle on one's life path through one's cultural landscape or 'figured world' and as such is a bridge for all who want to pass that way. But some models are not like that; turning an obstacle like "maths is hard" into an affordance as in "maths is challenging and I like a challenge" may be more possible for some students than others. It is as though different students are offered different landscapes to do their life journey through, that is, different social groups are offered different figured worlds. The educational institution and classroom, and pedagogy appear to provide different tools also.

To illustrate this, we now present Lee's story, a less positive account of his experience in studying mathematics and his disposition to continue doing so. This account is an abbreviated form of the story told in full in Williams and associates (2007) and within a different analysis in Black and associates (under review).

Lee also hopes to be the first in his family to go to university, although unlike Gemma, he says his mother has a fairly high status job which he describes as 'quite up there'. Lee is also less clear than Gemma regarding his future career trajectory stating that he wants to "get a good job" but "to get a good job, you got to go to Uni" - thus there are resonances with 'becoming a success' in his story. However, he is unclear regarding the subject he will study, proposing that this will be "... one of the subjects I am doing now at A level probably" [politics, psychology, sociology and maths]. Prior to secondary school, Lee describes his relationship with maths as fairly positive, stating "Yes. I was always good at maths, pretty much. (...) I got like top levels and stuff, in primary." However, this changed at secondary school where he says he lost interest due to a negative relationship with his maths teacher (nevertheless he achieved grade B in his higher GCSE). Despite his lack of interest, Lee chose to do AS level mathematics because "I wanted to do like a traditional subject, that would look good for University" but he says he struggled with the subject and by the end of the first term, it was suggested by his teacher that he change course to the 'easier' option of AS use of mathematics. 
Within his account, Lee rationalises his 'troubles' with the traditional AS level by explaining that his difficulties emerged out of his inability to keep on top of the workload. He states "it was like, loads of homework, and I just couldn't cope with

that. So it's my fault pretty much, for not going over my notes and stuff. But I didn't think I had to do that because I didn't have to do that at secondary [school]". However, despite use of mathematics being presented to him as 'easier', Lee has found the course to be "just as hard as the other ..." stating that "I don't get anything" and he predicts that he will fail.

When asked why his relationship with maths deteriorated, Lee draws on the cultural model of 'maths as too hard'. He says "it was like, you got all like harder stuff coming up obviously, like formula, and stuff like that" and "I was not getting anything, I was stuck. I can't do it." Furthermore, a central part of his narrative is his conjecture that he was 'misled' about the difficulty of the use of mathematics course - a key reason for why he is going to fail.

The way Lee constructs his story regarding his relationship with maths illustrates that not all students are equally positioned in terms of the cultural models they can draw on. Although, both Gemma and Lee view 'maths as hard', Lee uses this cultural model to position himself away from maths because it is 'boring' and 'not relevant'. We argue that his negative use of the cultural model 'maths as hard' may in fact be linked to his positioning in college and the classroom as marginalised from maths. He notes how he has been identified by his teachers as a 'struggling' student and at one stage he notes his lack of social integration in the use of maths class due to being seated on his own on the outskirts of the class (as a latecomer to the group). Thus, we argue that the way Lee uses the cultural model of 'maths is hard' in his lifestory is an attempt to position himself away from such a marginalised social position afforded by his teachers.

Consequently, both Gemma's and Lee's stories highlight how students' use of cultural models in their life stories may also be mediated by how they are positioned in the learning activity, for example by teachers and institutional policies (for example, institutional policy regarding who 'is' and 'is not' able to do mathematics). Gemma is given the space to construct her narrative around the notion that mathematics is 'challenging', providing potential energy to 'maths as hard' that could otherwise become 'maths is too hard'. This is despite only attaining a modest grade in GCSE mathematics which in another college (such as Lee's) would have prevented her from choosing to study AS level. In contrast, Lee's identity in college as a 'struggling' student has led to a sense of marginalisation from mathematics and his narrative is used to maintain a certain distance from the subject and thus reconcile his feeling of 'not belonging'. However, in another sense, the idea that mathematics as 'too hard, irrelevant and boring' may also provide potential energy to Lee's identity work - as one who does not see any 'use' for mathematics, as a non-mathematician, perhaps one who will study politics instead. Although there is not enough of a biography in the above account to see how this might work out positively yet (see Black et al., under review, for a follow up to his story): after dropping out of maths, he says in interview that he might be willing to study more mathematics (actually statistics) as he is now intending to study psychology at a top university and this may be required. 
Furthermore, the two accounts also show us that institutional conditions are clearly not the only source of difference that learners experience. Both these students were in a sense also positioned by their own personal experiences and histories - for instance as being the 'first' generation intending to apply to or attend university. This context had a manifestly significant impact on Gemma's account if not on Lee's. Additionally there may be elements of the two accounts that are gendered: we speculate that Gemma's relationship with her mother impacts particularly on her narrating that she doesn't want to 'end up like Mum'. We did not hear Lee say that he did not want to be like his Mum/Dad: but we must allow that he might bring something similar into his own story in some circumstances.

In similar accounts of other students' biographies, we have encountered narratives that make sense of class, ethnic or other factors that are known to be statistically salient (for example, working class students often choose to go to a local university, and ethnic minorities choose to go to those where the ethnic mix is friendly). So, for instance, Walter, another white working class student, tells of his family's health and housing problems - he lives next to a delinquent family who threaten violence against him and his kin - and how he as the oldest male in the family feels responsible for protecting his family. Consequently, he foresees himself studying at his 'home' university, even though this university does not offer his preferred mathematics course.

In summary, these narratives illustrate how in understanding life stories we need to look at how the cultural models used by students afford and constrain certain positions and dispositions towards or against mathematics. We also need to consider how and why such cultural models are drawn on by some to overcome 'troubles' and how they may be used to resource future dispositions. We suggested that one leading social influence might be a career ambition, social status or family kudos; in other cases we have tried and failed to detect any ambition or motive, with students apparently 'living in the moment'.

We have seen some indications that such students - that is, those without a driving ambition - may be particularly susceptible to local influences, including their social experiences of the mathematics classroom. For instance, some students told us that maths lessons were 'sociable' and 'fun', and one said this was the main reason for attending, as she had no intentions of progressing to university. However, not all students have access to these positive cultural models we have identified. While they have some agency in shaping their positioning, or disposition, students are not all equally positioned in society, in their institution or in their classrooms. One student finds herself with no 'real' graduates in her family to serve as 'models', but looks instead to the imaginary, fantasy world of films for a marine biologist graduate. Another student told us she has just one example of a graduate in her family, and that the person concerned had a bad time, ending a course with huge debts. She is unsure as to whether she should risk the experience, but is continuing at college anyway because there is nothing else to hand other than working in a shop. Thus background factors ensure that students may be unequally positioned even by the 'same' set of college and classroom conditions. We observe that only a holistic narrative of the students' trajectories can interweave these background factors with mathematical positioning and identity in an integrated, grounded account. 
The college institution too offers students differential access to maths. Some are accepted even though they arrive with a relatively risky, weak, previous mathematics grade whereas others are denied this by their college. Our case study fieldwork provides possible explanations: some colleges are themselves positioned differently from others in terms of funding and their student 'market'. In order to maintain a high reputation (through league tables of performance indicators) some colleges refuse to recruit weak students to mathematics courses, while other colleges opt out of this competition (or for other reasons are not so competitively positioned) and go for an 'open access' institutional policy that then puts a premium on making mathematics accessible to a wider group of learners. Similarly some classrooms offer a 'sociable maths' that is 'fun' and interactive, where for others the dominant model involves 'working on your own'. In this respect many students' narratives have suggested there is hope that pedagogy can really make a difference: apart from providing role models, the classroom or college institution may also offer multiple models of learning and hence 'ways of being' a learner of mathematics.

So, in conclusion, the stories of students show very different trajectories into or out of mathematics for students with very similar backgrounds: the students use cultural models in very different ways, and they position themselves differently according to (i) their 'leading ambitions' (if they have one) and (ii) the positions offered them by their colleges and teachers. The narrative analysis also shows how these diverse elements are interwoven and can build on their social, cultural and economic backgrounds. There is also a hint that college policy and pedagogy influences their trajectories. In the next section we will draw on a wider evidence base and theoretical framework to develop causal explanations.

\section{Cultural models as boundary objects between classroom practice and the narrative of identity}

In this section we draw on case studies of two teachers' classroom practice in the two contrasting institutions where Gemma and Lee were taught. The aim is to understand how these institutions and their pedagogies provided different cultural models of mathematics and offered different positioning to these students in virtue of their pedagogies and practices, and how it is that students adopt these in their narratives of mathematical identity. As such, this analysis closes the loop between narrative/biographical identity work and the social practices that resource this work.

Colin is a teacher of twenty years experience, and one that has won great respect from the college's senior management because of the results his students get. $\mathrm{He}$ was interviewed several times, and observed teaching the relevant mathematics students. His teaching might be described as 'interactive' but formal: this is how he described his teaching:

I mean normally, I, maybe I spend too long, you know, you know my sort of methods, it's nothing, it's old fashion methods, there's a bit of input from me at the front and then I try to get them working, practising questions as quickly as possible, and normally I'd spend quite a lot of time, but it tends to be now literally no more than twenty minutes on an exercise, I mean, some people say that's enough, really, and then, you know, move onto something else. 
Where in the old days I might have spent more time and have some harder questions at the end consolidating it, but not now. It tends to be as long as they can do the basics, then we'll move on, and we'll come back to it.

One thing that was striking in the observed lesson was the way he had simply 'told' the class the key idea for the topic: the formula to add together the terms of a geometric series, without any development, discovery, connection-making or motivation for the topic. Colin simply said "This is it, believe me, and this is what the examiners want ... now let's do these calculations". He often says he is "in a rush', both in the lesson and in the interview:

Int: you talk about rushing. I mean, did you feel you were rushing today?

Colin: Oh yeah. This is typical. This is what it's like all year.

Int: All the time...?

Colin: This is what it's like all the time. Because I feel the pressure on, I've got 25, 26 weeks in a year to get through 3 modules and this is how I feel, which is what I've got to do. You know, I would not call that teaching, what I did today. I don't think it is anyway. There might have been one or two good things in there but most of it is just trying to cram things in as fast as possible. And it is a nightmare but this is how it is. You know. Because at the end of the day, what I get judged on now is results. In September, results. You know, have they got the grades? And if they haven't, my head's on a block.

So it seems that Colin believes he cannot teach as he might wish because of the pressure of exams, grades and results - the instruments of audit. The institution holds him accountable for these, awards him praise for his performance.

Colin: Yeah, the results are everything.... it's not necessarily what you as a maths community would want, I don't think. I mean, this is me speaking here. This is not my department, necessarily, but I do tend to teach to the syllabus now. If it's not on, I don't teach it. I mean, I do try to bring some interest and explain things, if I can, but I do tend to say this is going to be on the exam, it's going to be worth X number of marks, that's why we're doing it.

There is in the above an interesting distancing from the 'maths community' (represented by the 'interviewer') by Colin: he sees the interviewer/observer as a member of this community, and thinks perhaps that his pedagogy is not what 'you' would want: he thus reflexively positions himself at a distance from the 'subject' culture here, in pressing his point about the significance of the institution's audit culture. He continues:

(...) the main thing is the shortage of time, but also we have a lot of students, I mean, maybe it's me over the years and it's worn me down, who are only doing maths because they have to do it, even at A level, because if they're doing medicine or whatever course, they need to have maths. And, although you try and get some interest, a lot of them, at the end of the day, the only way I can persuade them to do anything is - well it's worth ten marks on the 
exam paper.

To the institutional pressures on him to perform he now adds the pressure from the students, who he feels pressure him to stick to things that 'count' for them. Thus, the audit culture is again mediated through the students' own 'community culture': that is the community of students for whom performance on their exam is a passport to a university place. This audit culture is not attached to any particular community then, but is more like a Foucauldian, discursive 'regime of truth' that many communities can adopt to express their interests in the exchange value of the knowledge they expect to be created through pedagogy.

But exchange value cannot exist without use value (see also Williams et al., in press): audit can only maintain credibility of it is 'coupled' with a practical 'useful' evaluation that, in the last analysis, has some use-value (Power, 1997). Indeed, when pressed, Colin himself expressed ambivalence about the exams, as regards the development of a mathematical 'understanding' in particular.

His recollection of his own experience with 'not understanding' as a means of making sense of the 'tricks' pedagogy that he applies now: in part this involves an identification of himself as 'not a brilliant mathematician' and so presumably not unlike many of his students.

Colin: Yeah, ... and it is really teaching them the tricks. I mean, I admit, it's a bit like, I teach it the way I was taught really, which was teaching them the tricks. Because with me a lot of the understanding didn't come for maybe years and years and years, and (I) suddenly thought well that's why. I mean, in theory I've done a maths degree, and I'm not a brilliant, I still wouldn't say I'm a brilliant mathematician, and I think a lot of understanding does actually take years. And we haven't got years. I've got 26 weeks with the lower sixth and maybe a little bit more with the upper sixth. So I teach them the tricks. I mean, we do try to put the understanding, but you know, some of it is going to be, you take my word for this, it's going to work.

Int: You actually said that at one point in a lesson, I seem to remember...

Colin: I say it a lot, "Take my word for it."

Int: "We haven't time to prove it"?

Colin: Yeah, “even if you don't believe me, it's true", is one of my standard phrases. "Even if you don't believe me, it's true, it works, and it should work every time, hopefully... I could show you a proof of this, but they'll never ask you it, it's what you do with it that the exam board are interested in." So that's a classic thing now. In the old days I might have spent a bit of time trying to prove it to them.

In this explanation it seemed that Colin's personal history and relation to the 'subject culture' - mathematics as something that took years to understand, and he got by in the meantime as he hopes his students will now - by learning 'tricks'. But there is the problem with this approach, involving an inescapable contradiction: 
Colin: Well it is, yeah, I mean, it does lead, a lot of the time, it does lead them up the garden path. It tells them what to do, but even despite that some of them still can't; you know, they struggle with it. And unless it's set up exactly as the question was that I've shown them, they can't do it, and that's because they haven't got the deep understanding, and that's my fault, that is, in a sense. Because we've not given them the time to really learn how to, you know, when the question's slightly different, they can't cope with it.

Int: You're a bit ambivalent about understanding.

Colin: Sometimes you say you haven't got the time for it; that it comes later, but other times you say you actually do need it. ... Well, they do need it. For some of the questions they do need it. I teach them the tricks and hope that most of the time, that's enough to get them to do the exam questions, but, you know, if they set it in a slightly different way, they haven't got that understanding. Well, some, obviously the better ones pick up on it and they know how to adapt, but the weaker ones just haven't got a (clue?)... It's been going over their head a bit, certainly since Christmas it's been going over their head.

Thus, it seems in the 'end' tricks will not do, and understanding is needed to manage the harder parts of the course: on the one hand it is an unhelpful impedance of the performance his students must produce, but then it suddenly re-emerges as a requirement for later units. 'Understanding' turns out to have potential exchange value after all.

Colin seems here to be working out a professional identity at the nexus of several communities and cultures: the culture of institutionalised audit, where the exchange value of the knowledge is converted by the institution into resource and hence applies a very direct pressure he cannot ignore; the students' community and culture also mediates some of this same pressure to direct pedagogy at the test and hence to optimise the exchange value of their knowledge; and a rather underrepresented (by the researcher) subject culture that he uses as a counterfoil.

His own personal cultural history is also drawn on in the story from time to time, working his own experience of learning and understanding into his narrative alongside these community discourses and cultures. But there is conflict in his account, as he is presented with the 'fact' that for many students the performance of tricks eventually proves problematic. However, the end result, for the moment, is that the learners and their knowledge are objectified as exchange values, and use value is marginalised.

It was in this context that Lee was persuaded to drop out of Colin's class into one where the work would be found easier. Lee, you will recall, blamed himself because he could not keep up with the non-negotiable pace of work expected in Colin's class. (Bernstein and others researching in this framework, such as Morais (2002), have identified such 'strong framing' of pedagogy as a significant source of educational disadvantage).

Now, let us consider a 'successful student' from Colin's class: one who did quite well at GCSE and is set to do well in AS and A level: Steve intends to become an engineer. He says he enjoys maths, likes its 'closed' black and white character, and especially the fact that he can $d o$ it: 
Steve: It's just something to do. I enjoy it more than any other subject .... Well, I like physics ... maths and physics ... [are good for engineering]

Int: So what do you like about it?

Steve: I can do it. ... I [like] the questions that have got an answer...whereas in like, English literature or something, there's no answer as such. You can write anything as long as ... you can get away with pretty much anything, can't you? [Int: Yeah?] I don't like doing that because I prefer it if there's an answer there. [Int: ... how does it make you feel?] Well, it's easier to do.

Int: Easy. Yeah. Yeah. I mean, and these subjects like English, whatever you say in answer to a question, somebody might argue with you...

Steve: Yeah. And if you justify it, anything could be right

Steve's discourse is dominated by a 'positive maths identity for engineering' that in this case makes use of a cultural model of maths as 'black and white', nonnegotiable. It seems to make Steve feel safe, and it seems to be instrumental in two senses: on the one hand he 'feels he can do it' and so it has value for him in successful performance. On the other hand it is salient for engineering both in terms of 'use' and in terms of grade requirements, his future intended course and perhaps leading, imagined identity (at the moment).

In concluding the 'case' of Colin's pedagogic culture - we argue that this pedagogy that mediates the 'black and white' mathematical identity of Steve's and that this is a cultural artefact that is itself the outcome of a combination of (a) Colin's professional identity work and (b) the culture and discourse of various communities (the mathematical community, the institution of the college, and the student community). In Colin's case the culture is dominated by a discourse of 'audit' that foregrounds the exchange value of knowledge. But this is not without contradictions, and the professional cultural history of the teacher - and perhaps the intervention consequent on a research intervention such as ours - provokes some of this conflict in the teacher's discourse. We see the root of this conflict in the contradiction between use value of mathematics (understanding that will be useful to the student's engagement and performance later) and exchange value (getting the best performance on the test now, or soon).

In the next case we come via a similar analysis to a very different conclusion. Katrina is a student in Sonia's classroom, where Gemma had herself developed recently a positive disposition to maths. While Colin scored one of the highest scores on our 'teacher-centredness teaching scale', Sonia scored one of the lowest! (see Pampaka et al., 2007). So these two cases represent two extreme pedagogies in our study sample.

Here is part of Katrina's narrative, in which a very different pedagogy is implied:

Katrina: ... not only you think for yourself but like we can ask other people why they got that and it's not just black and white, like you get to a different way to work it out.' To give another example, 'yeah that's what I like as well, you can do it one way, somebody else can do it a different way, but you 
can still be both right and that's what's good, you find your own way. It is like a bit of independence as well I think in maths whereas other subjects you are taught what it is and everything, whereas maths you will go off and find what you want, it's good'. And alternatively, 'maths it's like really good, I didn't think I would enjoy it at all, I thought it would be boring, like at school it was pretty boring sometimes but, it's really good.'

It is interesting that this expression of a mathematical identity so closely contradicts that of Steve's on every main point: maths is characterised as not 'black and white', and is different from other subjects precisely because it is negotiable, arguable and in fact 'sociable'. Clearly, a different mathematical identity is being positively constructed here.

Observations of Sonia's classroom have been made on a number of occasions: we now have a very consistent picture of this pedagogy as being interactive, negotiable, connectionist, and for want of a better word 'mathematical' in the sense of expressing a 'mathematics culture'. A not untypical lesson has been analysed in Wake, Davis, Black, Hernandez-Martinez, Pampaka, and Williams (2007). As a snapshot we show the whiteboard in Figure 1 at the beginning of a lesson developing the concept of histograms. The teacher has put two rectangles on the board to represent the score of the upcoming world up match between England and Ecuador, and she asks 'what score might these represent?' As expected the responses include 1:2 and 1:4, and dealing with this conflict between linear and area representation seeds the notion of area representing frequency later in the lesson. (Incidentally, the provocation of key errors that suggest conceptual conflict is one of Sonia's general strategies).

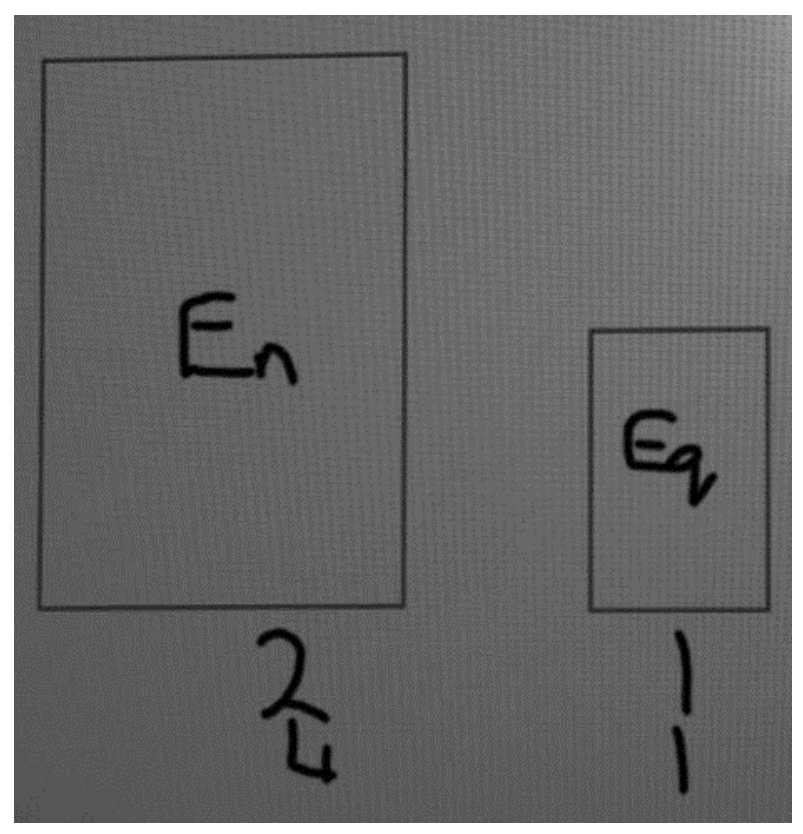

Figure 1. Sonia's start to the lesson on histograms 
In another typical episode of a lesson on functions, she asks the class for suggestions as to the formula for a graph she has put on the board. She collects five different responses and reflects "Well, they can't all be right I suppose... how will we decide which are right and which are wrong?" The emphasis here is on the mathematical productions of the students themselves, who she often appeals to as 'mathematicians': they are exhorted to 'think like mathematicians'. The use of the collective 'we' in the quote above is also reflective of her appeal to the class to act as a mathematical community.

In the following section of interview it becomes clear that Sonia's view of her own pedagogy is mediated by a 'maths subject culture': she wants her students to think like mathematicians, to enjoy solving problems and - in the end - to be mathematicians:

Yeah, that is really important. But they don't think ... there's the self-esteem. Just general self-esteem, not just Maths, but also from the maths point of view, because I mean let's face it ... you know ... Because there are a lot of maths you get things wrong, (don't) you? But I want them to realise that's how mathematicians work. ... Because I want them to realise that, yeah, they are mathematicians. They are not just students who are struggling with maths. I think this is really important for them ... Whereas, every time you get stuck you don't have to ask the teacher for help. You are not a baby trying to learn something ... I don't want to think about the people I met at university, certainly ... But I think of mathematicians as somebody who enjoys solving problems and who will keep going on with a problem until he gets something out of it. And they don't mind getting it wrong and they don't worry about how many sheets of papers they use and they just enjoy solving problems.

There are clear signs in the interviews that the institutional culture mediates an audit culture, for instance in the need to optimise league table results, but for various reasons this does not come to dominate Sonia's discourse or her pedagogical practice. Some of these reasons lie at the door of the college institutional and community context: being geographically situated in a place where they do not directly compete with other colleges for 'good students' - at least the competition is not as severe as at Colin's college. But also, serving a very poor, isolated and deprived community, the college is obliged economically to recruit less well prepared students and help them succeed to be economic.

But in addition, our analysis shows some clear threads of cultural history in her narrative: her own experience of 'coming from round here', becoming an excellent and very confident mathematician by having to think things out for herself as 'lectures never made sense', and recently gaining kudos as a leading member of her 'subject' culture, the mathematics education community. There is not sufficient space to develop all the evidence for this here, but we note these factors are prominent in supporting her pedagogical narrative and capacity for action in negotiating between 'audit' and 'subject' cultures in her particular college.

In the end however, while we point to factors, we cannot really know definitively how the two professional identities of Colin and Sonia have historically emerged: perhaps the complete narration of the cultural-historical development of identity can never be fully and definitively told. 
In conclusion, we have shown how distinct pedagogies can help position learners in different ways and provide different cultural models of mathematics in social practice and how they resource the identity work of the students who engage in these different practices. These different pedagogies can position students in relation to mathematics in distinct ways, for example for understanding rather than for performance, as 'struggling' or as mathematicians 'having a go', and these can be internalised by students. The cultural models of mathematics as "black and white/not black and white", "lonely/sociable" or "hard/challenging" perform at the boundary of two activities: the classroom activity mediated by the pedagogy and the narrative activity in which the students account for their aspirations and narrate their identity. So we see pedagogy as providing for at least partial explanations of how students' trajectories of identity can be differently resourced. But we note here also how pedagogy is not simply an act of free will of a teacher and their beliefs. A teacher's cultural history seems in itself to combine with a college's institutional and community culture in mediating pedagogy. We recognise and value the professional identity of the teacher, and regard their cultural history as a critical explanation of this identity. But we also doubt that this professional self-identity would be sufficient to determine pedagogy in itself: as pedagogy is itself essentially mediated by the local institutional and community cultures.

Methodologically, we here note that these two cases relied not only on the learners' discourses and narratives, but also on the observations of lessons, and the interviews of the two teachers involved. This approach is sustained by the CHAT framework that suggests that we need to examine mathematical identity in relation to joint mathematical activity (and vice versa). Thus the self-identity of the teacher and student - as witnessed in interview activity - are bound up through the activity of classroom, in teaching-and-learning practices. Pedagogy is a product of the cultural history of the teacher that is crystallised in their professional identity, the teachers' professional habitus. But not only that - it is also mediated by the complex of institutional, community and subject cultures that may reflect the power of audit as well as the use value of mathematics. But the community culture reflects as well as engages with the identities of the learners, so that pedagogy is at the nexus of a constellation of teachers' and learners' identity work (in Wenger's, 1998, terms) or is an activity that bounds a series of institutional, 'home' and professional activity systems that are in various ways in conflict with each other.

\section{CONCLUSION}

We began this chapter by suggesting that the three analytical approaches used here should offer different affordances. Our approach to 'interpretative repertoires' was parsimoniously and deliberately limited theoretically, and we find this appropriate to the empirical project of mapping the repertoires used cross-sectionally across our data sets. Some would call this a 'grounded theory' approach: themes are defined by a 'common sense' interpretation as befits a 'common sense-ical' interpretation of 'interpretative repertoires'. This makes the observation that aspirational styles are socio-culturally related a powerful empirical finding (albeit with our special, small sample). The implications for policy in terms of widening participation in mathematics seem clear: policy needs to address youngsters in the languages they understand if they are to receive an interested audience. But the 
'language they understand' is different for different groups of students and is related to this in complex, intersectional ways involving at least ethnic, gender and class backgrounds: for some students mathematics needs to offer personal satisfaction here and now, for others its exchange value is vital to motivation, and for yet others vocational 'use' is significant. We know the media can be important too in providing models, perhaps for students that have few alternative aspirational resources. Unfortunately we are not convinced this 'mapping' is complete, and we are aware that the results of this small sample have revealed 'intersectionality' of background factors that need further research. Nevertheless this work is promising in suggesting the potential efficacy of developing such an empirical map.

The analysis of biographical narrative on the other hand provides much more complexity 'in the whole' at the cost of focussing on fewer students: it becomes clear that narratives can be constructed from cultural models in different ways according to how the subject seeks to position themselves, and that this relates to how others position them in various other salient activities. Then there are the consequences of this self- and other- positioning for their other identities: inevitably one's engagement in different activities in which one is differently positioned provides us with contradictions. We suggest that the narrative is a way of reflecting on and working out such contradictions, or repairing the troubles. For instance, if one is a 'sociable' person in general, say in one's home life, one may find it difficult to self-identify with mathematics unless it is presented as a potentially sociable activity. Similarly Katrina liked the fact that mathematics was an argumentative subject, in which everyone can express their point of view. Recall, though, that Steve liked mathematics precisely because it was 'black and white', and so could not be used to challenge his answers. Thus it might be inferred the presentation of cultural models of mathematics and mathematicians has an important self-selecting effect on the kinds of people who will take up mathematics and what sort of mathematicians they may become.

However, a CHAT analysis of the activity of narration as we constructed it raises fundamental epistemological questions about this analysis and its findings (see Roth et al., 2005). Quite apart from the essentially post hoc storying of the students accounts, as interviewers do we not co-construct the narrative with the student in ways that we find 'satisfying'? Can we convincingly draw conclusions for identity and classroom practice based on these narratives alone?

Finally the analysis of cultural models at the boundary between mathematical practice (mediated by pedagogy, professional identity of the teacher, and in turn subject-, institutional and community cultures) and narrating the self allows us to explain trajectories of identity into or out of mathematics. We argued that positioning of the self in narratives is also critical and that this positioning is explained partially by the way learners are positioned in the institution and the classrooms in which they engage in practice, for example by pedagogy and institutional practices. The result was substantively powerful for mathematics education, as the contrast between two pedagogies could be seen in the narratives of the students, via the mediation of cultural models of ways of being mathematical and ways of doing mathematics. This explanatory power comes with a price in terms of the complexity of the data and analysis it demands, however, and even in this lengthy chapter we have not had the space to develop our analyses of the two teachers own narrative history - that is another story. 
Still, this investment seems to be essential for getting at the teaching and learning practices that can really make a difference to student disposition to engage, which is the key aim of our research project. Although the additional perspectives from the classroom, the college and the teachers can perhaps never be fully told (one has to stop somewhere) we argue that a minimal account must engage with the teacher and the student engaged in 'joint object orientated' practice.

\section{REFERENCES}

Bernstein, B. (1996). Pedagogy, symbolic control and identity. London: Taylor \& Francis.

Black, L., Davis, P., Hernandez-Martinez, P., Pampaka, M., Wake, G., \& Williams, J. (under review).

Imagined futures: Mediation of the mathematical biography. Paper under review for Educational Studies in Mathematics.

Boaler, J., \& Greeno, J. (2000). Identity, agency and knowing in mathematics worlds. In J. Boaler (Ed.), Multiple perspectives on mathematics teaching and learning (pp. 171-200). Westport: Ablex Publishing.

Bourdieu, P. (1984). Distinction: A social critique of the judgment of taste. Cambridge, UK: Cambridge University Press.

Bruner, J. (1996). The culture of education. Cambridge, Massachusetts: Harvard University Press.

Cole, M. (1996). Cultural psychology: A once and future discipline. Cambridge, Mass: Belknap Press of Harvard University Press.

DFES. (2008). Table 40b: Achievements at GCSE/GNVQ in 2003, by ethnicity, Free School Meal provision and gender. Retrieved June 23, 2008, from http://www.dfes.gov.uk/rsgateway/ DB/SFR/s000448/table37-40.xls

Daniels, H. (2001). Vygotsky and pedagogy. London: Routledge Falmer.

Davis, P., Williams, J., Black, L., Hernandez-Martinez, P., Pampaka, M., \& Wake, G. (2007). Students' mathematical identity and its relation to classroom mathematics social practice. Paper presented at the British Educational Research Association Conference, Institute of Education, London. [Unpublished document]

Engeström, Y. (1999). Activity theory and individual and social transformation. In Y. Engeström, R. Miettinen, \& R.-L. Punamäki (Eds.), Perspectives on activity theory (pp. 19-38). Cambridge: Cambridge University Press.

Evans, G. (2006). Educational failure and working class white children in Britain. Basingstoke, UK: Palgrave, Macmillan.

Gee, J. P. (1999). An introduction to discourse analysis: Theory and method. London: Routledge.

Gee, J. P. (2001). Identity as an analytic lens for research in education. Review of Research in Education, 25, 99-126.

Hernandez-Martinez, P., Black, L., Williams, J., Davis, P., Pampaka, M., \& Wake, G. (2008). Mathematics students' aspirations for higher education: class, ethnicity, gender and interpretative repertoires and styles. Research Papers in Education, 23(2), 153 - 165.

Holland, D., \& Quinn, N. (1987). Cultural models in language and thought. Cambridge: Cambridge University Press.

Holland, D., Lachicotte, W., Skinner, D., \& Cain, C. (1998). Identity and agency in cultural worlds. Cambridge: Harvard University Press.

Jenkins, R. (2004). Social identity. London: Routledge.

Kaasila, R. (2007). Using narrative inquiry for investigating the becoming of a mathematics teacher. ZDM - International Journal of Mathematics Education, 39(3), 205-213. Lakoff,

K., \& Johnson, M. (1999). Philosophy in the flesh. New York: Basic Books.

Leont'ev, A. N. (1978). Activity, consciousness and personality. Englewood Cliffs, NJ: Prentice Hall.

Leont'ev, A. N. (1981). Problems of the development of the mind. Moscow: Progress.

Morais, A. (2002). Basil Bernstein at the micro level of the classroom. British Journal of Sociology of Education, 23(4), 559-570.

National Statistics Online. (2008). Population size. Retrieved June 23, 2008, from http://www.statistics.gov.uk/cci/nugget.asp?id=273 
Pampaka, M., Black, L., Davis, P., Hernandez-Martinez, P., Wake, G., \& Williams, J. (2007). Measuring the 'effectiveness' of programme and pedagogy on maths disposition and self efficacy measures. Paper presented at the British Educational Research Association Conference, Institute of Education, London. [Unpublished document]

Potter, J., \& Wetherell, M. (1987). Discourse and social psychology, beyond attitudes and behaviour. Sage: London.

Power, M. (1997). The audit society: Rituals of verification. Oxford: Oxford University Press.

Roth, W.-M., \& Lee, Y.-J. (2007). "Vygotsky's neglected legacy": Cultural-historical activity theory. Review of Educational Research, 77(2), 186-232.

Roth, W.-M., Hwang, S., Lee, Y.-J., \& Goulart, M. I. M. (2005). Participation, learning, and identity: Dialectical perspectives. Berlin: Lehmanns Media.

Stetsenko, A., \& Arievitch, I. M. (2004). The self in cultural-historical activity theory: Reclaiming the unity of social and individual dimensions of human development. Theory and Psychology, 14(4), 475-503

Sfard, A., \& Prusak, A. (2005). Telling identities: In search of an analytic tool for investigating learning as a culturally shaped activity. Educational Researcher, 34(4), 14-22.

Wake, G., Davis, P., Black, L., Hernandez-Martinez, P., Pampaka, M., \& Williams, J. (2007) Pedagogic practices and interweaving narratives in AS Mathematics classrooms. Paper presented at the British Educational Research Association Conference, Institute of Education, London. [Unpublished document]

Wells, G. (1999). Dialogic inquiry: Towards a sociocultural practice and theory of education. Cambridge, UK: Cambridge University Press.

Wenger, E. (1998). Communities of practice: Learning, meaning and identity. Cambridge: Cambridge University Press.

Wertsch, J. V. (1991). Voices of the mind: A sociocultural approach to mediated action. Cambridge, MA: Harvard University Press.

Williams, J. (2007). Community, culture, and identity: Pedagogy as mediation between teacher's and learner's identity?. Paper presented at the 2nd ScTIG conference, Manchester, UK. URL: http://www.lta.education.manchester.ac.uk/TLRP\test.htm

Williams, J., Black, L., Hernandez-Martinez, P., David, P., Hutcheson, G., Nicholson, S., \& Wake, G. (2007). Storying mathematical identities with cultural models. In D. Pitta-Pantazi, \& G. Philippou (Eds.), Proceedings of the Fifth Conference for European Research in Mathematical Education (CERME 5). Larnaca: University of Cyprus. [On line: http://ermeweb.free.fr/CERME5b/]

Williams, J., Corbin, B., \& Macnamara, O. (2007). Finding inquiry in discourses of audit and reform in primary schools. International Journal of Educational Research (Special Issue, Edited by J. Williams, P. Davis, \& L. Black), 46(1-2), 57-67.

Williams, J., \& Wake, G. D. (2007a). Black boxes in workplace mathematics. Educational Studies in Mathematics, 64, 345-371.

Williams, J., \& Wake, G. D. (2007b). Metaphors and models in translation between college and workplace mathematics. Educational Studies in Mathematics, 64(3), 345-371.

Willis, P. (1977). Learning to labour: Why working class kids get working class jobs. Columbia: Columbia University Press

Yin, R. K. (1989). Case study research: Design and methods. Newbury Park: Sage Publications. 